\title{
A cross-cultural study of disagreement strategies to suggestions between Persian EFL learners and American native English speakers
}

Bavarsad, Samira Salehipour

English Department, Najafabad branch, Islamic Azad University, Najafabad, Iran (Samira.salehipour@gmail.com)

Eslami-Rasekh, Abbass

English Department, Najafabad branch, Islamic Azad University, Najafabad, Iran (Abbasseslamirasekh@yahoo.com)

Simin, Shahla

English Department, Najafabad branch, Islamic Azad University, Najafabad, Iran (shahlasimin@yahoo.com)

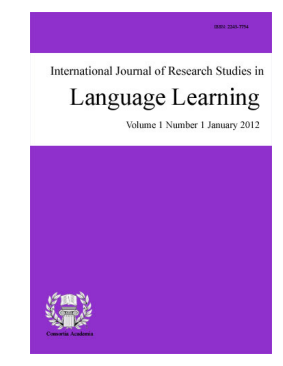

ISSN: $2243-7754$ Online ISSN: 2243-7762

OPEN ACCESS

Received: 26 January 2015

Revised: 18 February 2015 DOI: $10.5861 /$ ijrsll.2015.1085

Accepted: 20 February 2015

\section{Abstract}

The speech act of disagreement is one of the areas of research that has not received much attention in the Iranian context. The focus of this study is to investigate the ways in which this act is expressed by Persian EFL learners and American native English speakers. To collect the data 140 participants (100 Persian EFL learners and 40 American native English speakers) were selected randomly from among undergraduate and graduate students of University of Isfahan and Islamic Azad University (Najafabad branch) majored in English and from Concordia University in Ann Arbor, Michigan. This study is an attempt to find out the role that power might play in the employment of strategies to mitigate the threat of the act of disagreement in two nations. Students were asked to complete a discourse completion test (DCT) designed by the researcher. They were supposed to read nine situations, and react to them via making disagreements. Respondents were expected to disagree with three interlocutors with higher status, three peers and three with lower status. In order to analyze the utterances of disagreement, Muntigl and Turnbull's taxonomy (1998) was employed. The results revealed that although both nationalities were concerned about the power status of interlocutors and try to apply the appropriate strategies while expressing their disagreements, Persian EFL learners were more cautious.

Keywords: speech act; disagreement; power; gender 


\section{A cross-cultural study of disagreement strategies to suggestions between Persian EFL learners and American native English speakers}

\section{Introduction}

Recently, many researchers have shifted their focus form emphasizing the formal components of a language to highlighting the appropriate use of language. Regarding this view speeches are employed as instruments to perform different actions such as expressing apology, thanks, disagreement, making requests, etc. (Yule, 1996). As mentioned in Brown and Levinson theory (1987), some of the speech acts are face threatening by nature because of neglecting the face wants of interlocutors. They define the face threatening acts (FTAs) according to the person whose face is being threatened and the type of paying no attention to the face (negative/positive face) and also mention that when one speaker does not consider the self-image of the addressee the positive face has been neglected and whenever there is a pressure on the addressee to accept or reject the future act of the speaker there has been a case of neglecting the negative face.

The speech act of disagreement is considered as a face-threatening verbal behavior in which people can show their dissatisfaction or opposition; therefore, applying an appropriate strategy to show disagreement to interlocutors with different social statues can decrease the possible danger of threatening the face of the addressee. Power can play a crucial role in the process of selecting strategies; Brown and Levinson (1987) for example assert that "power is an asymmetrical social dimension of relative power" (p. 77). But for Liu (2004) power means status in which professors, administrators, and students are on a hierarchy from powerful to powerless. The relative power of the addressee, the degree of imposition and the social distance that exists between the speaker and the addressee are the main points that an individual considers to estimate the degree of the seriousness of an FTA (Brown \& Levinson, 1987).

\section{Literature review}

The functional goals of speech have attracted many researchers to this area of traditionally neglected aspect of language function. During the process of learning a foreign language there may be some learners who are found to be fluent due to their correct use of grammatical and lexical knowledge but they cannot be expected to be able to have successful conversations according to the social and cultural norms, this assumption shows there is still a gap in pragmatic competence. As Brown and Levinson (1987) declare in their theory of politeness, many speech acts such as requesting, criticizing, and disagreeing are intrinsically face threatening. Speech acts are threatening because they do not consider the face wants of the interlocutors. Brown and Levinson (pp. 65-67) defined face-threatening acts (FTAs) according to two basic variables: (1) Whose face is being threatened (the speaker's or the addressee's), and (2) Which type of face is being threatened (positive- or negative- face).

As Simin et al. (2014) mentioned "the language proficiency does not guarantee the communicative efficiency" (p. 72), in order to produce the most appropriate and polite speech act (e.g. disagreement), the formal knowledge of the related language in not enough by itself; therefore, one should be aware of the pragmatic knowledge at the same time. In a cross-cultural study by Dogancay-Aktuna and Kamisli (1996) a comparison was drawn between the native speakers of Turkish and American English in terms of applying discourse strategies they. The study revealed that although the status difference was an important factor in the American setting, it was not much serious in the Turkish working place interaction. The researchers also found that Americans were more cautious about using initial positive remarks and politeness markers to redress their disagreements.

Another study by Guodong and Jing (2005) looked at American and Japanese performance on the face threatening act of disagreement. All the participants were asked to fill in a DCT designed by the researchers. The 
Disagreement strategies to suggestions between Persian EFL learners and American native English speakers

DCT included five scenarios and the participants were supposed to write what they would say when they disagree with an addressee in higher-status, peers and lower-status. The results revealed that, Chinese students pay more attention to the face-wants of their addresses. A positive correlation was also found between the rates of disagreement and the change of the social distance for the Chinese students while a negative correlation seemed to exist for the American students. Female students were also observed to be more conservative while expressing opposition.

The result of one study conducted by Pilkington (1992) revealed the importance of gender in applying appropriate strategies for expressing disagreement. Respondents were a group of both male and female workers in New Zealand. In this study females were found to employ a lot of agreement and positive feedback while males tended to use more direct ways of expressing opposition. In another study, Mehregan et al (2013) examined the possible role of gender on the process of employing suitable strategies for showing disagreement. For this aim, 42 undergraduate students including 21 males and 21 females participated in this study and they were also asked to answer the six both formal and informal scenarios of the DCT. After analyzing the data the results showed that the degree of formality of the female participants was more than that of males. The study also revealed that a positive correlation exists between the degree of conservativeness and level of formality in the scenarios of the DCT.

Kreutel (2007) conducted a study the focus of which was on the differences in applying disagreement strategies between by 27 native speakers and 27 non-native English speakers for expressing their opposition to an interlocutor. The results showed that non-native speakers employ the undesirable features with a higher degree of frequency. It was also found that mitigation devices such as explanations or hedges had the lowest degree of frequency among the strategies used by non-native speakers. In another cross-cultural study, Nguyen (2009) compared the disagreement strategies applied by Vietnamese and American students. The American participants of the study were found to be more careful about the face wants of their addresses, but the Vietnamese interlocutors used more direct and aggressive strategies while expressing opposition. After comparing the strategies employed by both male and female participants, it was also found that the male respondents of both groups tended to be more direct than the female respondents.

Parvaresh and Eslami rasekh (2009) investigated the performance of young Iranian women can be affected by the level of solidarity and deference which exists in the context of conversation. Leech's classification of illocutionary functions was used to reveal that when young women disagree with males the considerations of deference might override those of solidarity but when their addressee is of the same sex they sometimes use the conflictives which have the most impolite intention. While, Behnam and Niroomand (2011) used a proficiency test to divide the participants in to two groups (Intermediate, Upper-Intermediate) and then data were collected via a DCT. The study suggested a mutual relation between politeness strategies in showing disagreement to addressees with different power status; more importantly, as even the performance of the learners with a high level of proficiency was far from that of the native speakers, the researchers concluded that L2 learners must be aware of second language socio-cultural constraints as well as grammatical rules to have a successful communication. Therefore, based on the results of the studies mentioned above, more attention should be paid on the cultural and cross-cultural differences of applying different strategies to show disagreement. So, there is a need for further research on the pragmatic competence of Persian EFL students in all aspects. This study can be considered as an attempt to fill in this gap.

\section{Methodology of the study}

The focus of this study is on the following research questions:

$>\quad$ How do Persian EFL learners and native English speakers perceive power and can this factor affect their choice in applying disagreement strategies?

Do Persian EFL learners use the same strategies to show disagreement as do American English 
Bavarsad, S. S., Eslami-Rasekh, A., \& Simin, S.

speakers?

$>$ Do Persian EFL learners use more polite strategies for showing disagreement?

\subsection{Participants}

The participants of this study consisted of 100 Persian EFL learners, including 50 males and 50 females, studying in Islamic Azad University, Najafabad branch, Iran and also in University of Isfahan, Isfahan, Iran. There were also 40 participants (20 males, 20 females) studying in Concordia University in Ann Arbor, Michigan. The participants' age ranged from 19 to 36 .

\subsection{Instruments}

To collect data for this study, a Discourse Completion Test (DCT) was designed and applied. The DCT is a form of questionnaire describing some natural situations to which the respondents are expected to react, making disagreement. In this case the (DCT) consists of nine scenarios, in which the subjects were expected to disagree with three higher statuses, three peers and three with a lower status and then, they were also asked to write their natural responses for each situation.

\subsection{Data collection}

Prior to the actual data collection, a pilot study was conducted. The modified form of the (DCT) was given to a professor for validation. His suggestions and observations were well taken into consideration in designing the final form of the (DCT). For further validation, the (DCT) was piloted on 15 EFL Persian learners and 5 native English speakers, similar to the main groups, not included in the sample to see if the language was comprehensible for subjects, and based on their responses a few changes were made.

The final DCT was administrated to participants. Selection of disagreement situations in DCT was based on social factor of relative power. The DCT consists of nine scenarios, in which the subjects were expected to disagree with three higher statuses, three with peers and three with a lower status. The questionnaire describes situations that both Persian and American speakers may counter in everyday life and seeks to elicit responses to such situations and all of these situations were grouped according to power and distance among interlocutors. The scenarios covered a variety of topics and types of situations to avoid intervening effects of topic selection. The participants were asked to produce appropriate and natural disagreement utterances for a given context of situations in DCT.

\subsection{Data analysis}

Data required for the study were analyzed in three steps. First, invalid responses were discarded and the total number of valid responses was determined. In the second step, for identifying the utterances of disagreement from the responses, Muntigl and Turnbulls' (1998) taxonomy was used. By this taxonomy five types of disagreement are identified: Irrelevancy Claims (IC), Challenges (CH), Contradictions (CT), Counterclaims (CC) and the combination of contradictions followed by counterclaims. Finally, the frequencies and percentages were calculated to compare the mighty differences between two nationalities.

\section{Results}

The subjects of the study were supposed to read and react naturally to nine scenarios in the DCT within which the social distance between the interlocutors and their status relative to each other were taken into account. We predicted a possible relationship between power and the application of strategies for showing disagreement to interlocutors with different social status. In this part, the analysis shows the results in both qualitative and quantitative ways. 


\subsection{Situation 1}

You visit your doctor due to your continuous headaches. He believes that you must change your method of treatment but you are completely satisfied with this method and you disagree with the doctor.

You say: "

In this situation, the speaker who is being disagreed with is of a higher power level due to his position. The data displayed a clear effect of the addressee's power on formulating the expression of disagreement.

\section{Table 1}

Situation 1: Disagreement with the doctor

\begin{tabular}{llcccc}
\hline \multirow{2}{*}{ Types of disagreement } & \multicolumn{3}{c}{ Native } & \multicolumn{2}{c}{ Persian } \\
\cline { 3 - 6 } & $f$ & $\mathrm{P}$ & $f$ & $\mathrm{P}$ \\
\hline 1 & Irrelevancy claims & 0 & 0 & 1 & $1 \%$ \\
2 & Challenges & 15 & $37.5 \%$ & 6 & $6 \%$ \\
3 & Contradictions & 20 & $50 \%$ & 24 & $24 \%$ \\
4 & Counterclaims & 4 & $10 \%$ & 13 & $13 \%$ \\
5 & Contradictions followed by counterclaims & 0 & 0 & 14 & $14 \%$ \\
\hline Note. F= frequency, P = percentage & & &
\end{tabular}

According to Table 1, in Persian EFL learners group CT with $24 \%$ is the most favored strategy (e.g. No, this method is good) and only $1 \%$ of the subjects preferred IC as the most face threatening strategies (e.g. You're not worth on money and fee!) and in native English speakers group the highest frequency is related to CT with $50 \%$ (e.g. No doctor, no!). Although in this situation IC is not applied at all by native speakers, the high frequency of $\mathrm{CH}, 37 . \%$, the second face threatening strategy, (e.g. e.g. But why?) shows native English speakers pay less attention to the face of the addressee even one in higher status.

\subsection{Situation 2}

You are driving on a highway that the police stops you and then fines you for not paying attention to the signs. He suggests you that it's better to participate in new classes of driving course which reeducates and reminds the signs. You feel no need to do this.

You say: "

This situation seems to be exactly the same as previous one which shows disagreement with an interlocutor in higher position and the same inconsistency exists between the powers of interlocutors.

Table 2

Situation 2: Disagreement with a police officer

\begin{tabular}{llcccc}
\hline \multirow{2}{*}{ Types of disagreement } & \multicolumn{2}{c}{ Native } & \multicolumn{2}{c}{ Persian } \\
\cline { 3 - 6 } & & $f$ & $\mathrm{P}$ & $f$ & $\mathrm{P}$ \\
\hline 1 & Irrelevancy claims & 0 & 0 & 6 & $6 \%$ \\
2 & Challenges & 5 & $12.5 \%$ & 1 & $2 \%$ \\
3 & Contradictions & 14 & $35 \%$ & 57 & $57 \%$ \\
4 & Counterclaims & 0 & $22.5 \%$ & 10 & $10 \%$ \\
5 & Contradictions followed by counterclaims & 0 & 0 & 3 & $3 \%$ \\
\hline Note. F= frequency, P = percentage & \multicolumn{3}{c}{. }
\end{tabular}

As Table 2 shows, the highest frequency in Persian learners group (57\%) is related to applying CT (e.g. No sir, I think it's not necessary, I may study the book again) and the least favored strategy is $\mathrm{CH}$ with $2 \%$ (But why? Just because of a small mistake!). For native English speakers group CT with highest frequency of 35\% comes first (e.g. No way!). As it can be seen $\mathrm{CH}$ (e.g. Why? Just for one mistake?!) again is much more used with native English speakers (12.5\%) comparing Persian speakers. 


\subsection{Situation 3}

You see your child's school principal. He tells you it's better to change your child's major because its future will not be so good. You think contrary to him and your child is successful in this field. Then you disagree with him.

You say:"

In this situation, the interlocutor who is disagreed with is still a male in a higher position but in comparing with previous two situations the social power is considered to be somehow less.

Table 3

Situation 3: Disagreement with child's school principal

\begin{tabular}{llcccc}
\hline \multirow{2}{*}{ Types of disagreement } & \multicolumn{2}{c}{ Native } & \multicolumn{2}{c}{ Persian } \\
\cline { 2 - 6 } & $f$ & $\mathrm{P}$ & $f$ & $\mathrm{P}$ \\
\hline 1 & Irrelevancy claims & 0 & 0 & 1 & $1 \%$ \\
2 & Challenges & 1 & $2.5 \%$ & 3 & $3 \%$ \\
3 & Contradictions & 15 & $37.5 \%$ & 17 & $17 \%$ \\
4 & Counterclaims & 16 & $40 \%$ & 29 & $29 \%$ \\
5 & Contradictions followed by counterclaims & 0 & 0 & 5 & $5 \%$ \\
\hline Note. F= frequency, P = percentage & & & &
\end{tabular}

Regarding Table 3, in this situation Persian learners tended to apply CC (e.g. I respect your opinion but I think It's better he continues with this major) more (29\%) which is considered as a polite way of showing disagreement that speakers try not to violate the face of the addressee. Native English speakers also preferred CC (e.g. You are so kind to think of him, but not possible) more than the other strategies (40\%). As the table shows, in this situation Persian speakers applied IC (e.g. It's none of your business) and $\mathrm{CH}$ (e.g. What's the problem with this major? It's all right.) strategies more than native English speakers.

\subsection{Situation 4}

By coincidence, you see one of your old colleagues, Mr. Ahmadi, in the street and he tells you to change your hairstyle because it's not beautiful and you look older. Unlike him, you like this style a lot.

You say:"

In this situation, the interlocutors are status equal. Here, the major point which makes the difference is the gender of the speaker in scenario that considers females with a lower status power.

\section{Table 4}

Situation 4: Disagreement with an old colleague

\begin{tabular}{llcccc}
\hline \multirow{2}{*}{ Types of disagreement } & \multicolumn{3}{c}{ Native } & \multicolumn{2}{c}{ Persian } \\
\cline { 2 - 6 } & $f$ & $\mathrm{P}$ & $f$ & $\mathrm{P}$ \\
\hline 1 & Irrelevancy claims & 3 & $7.5 \%$ & 4 & $4 \%$ \\
2 & Challenges & 6 & $15 \%$ & 24 & $24 \%$ \\
3 & Contradictions & 20 & $50 \%$ & 18 & $18 \%$ \\
4 & Counterclaims & 4 & $10 \%$ & 4 & $4 \%$ \\
5 & Contradictions followed by counterclaims & 1 & $2.5 \%$ & 1 & $1 \%$ \\
\hline Note. $\mathrm{F}=$ frequency, $\mathrm{P}=$ percentage & & & &
\end{tabular}

As Table 4 represents, the shift in power from high to peers causes the subjects in both nationalities to feel more free to use face threatening strategies to disagreement. As it can be seen the highest percentage $(24 \%)$ in Persian speakers group is related to $\mathrm{CH}$ (e.g. Did I ask you for your opinion?) and in native English speakers group there is an increase in applying these face threatening strategies. 


\subsection{Situation 5}

You are speaking with a neighbor and she suggests changing the caretaker of the building because she isn't pleased with him, but you are completely satisfied with him and reject this suggestion.

You say:" ."

Just like the forth situation within which gender was the determining factor, this situation and the sixth one seem to be similar, as here the interlocutors are status equal.

\section{Table 5}

Situation 5: Disagreement with a neighbor

\begin{tabular}{llcccc}
\hline \multirow{2}{*}{ Types of disagreement } & \multicolumn{2}{c}{ Native } & \multicolumn{2}{c}{ Persian } \\
\cline { 3 - 6 } & & $f$ & $\mathrm{P}$ & $f$ & $\mathrm{P}$ \\
\hline 1 & Irrelevancy claims & 0 & 0 & 2 & $2 \%$ \\
2 & Challenges & 6 & $15 \%$ & 3 & $3 \%$ \\
3 & Contradictions & 17 & $42.5 \%$ & 25 & $25 \%$ \\
4 & Counterclaims & 7 & $17.5 \%$ & 31 & $31 \%$ \\
5 & Contradictions followed by counterclaims & 0 & 0 & 18 & $18 \%$ \\
\hline Note. F= frequency, $\mathrm{P}$ = percentage & & & &
\end{tabular}

Regarding table 5, the most used strategies by Persian speakers was CT (e.g. No, we will warn him.) with $25 \%$ of occurrence and in native English speakers this strategy also appeared to be the most favored one (e.g. No, he is ok). But the percentage of applying $\mathrm{CH}$ (e.g. Why? Is he careless?) as one of the face threatening strategies was higher by native English speakers

\subsection{Situation 6}

You buy a piece of clothes and come back home. When you put it on, your spouse says this color is not good on you and it's better to change the color. You disagree.

You say:"

In this situation, the interlocutors are still equal but the close relationship between the spouses makes it different from the two previous situations.

\section{Table 6}

Situation 6: Disagreement with spouse

\begin{tabular}{llcccc}
\hline \multirow{2}{*}{ Types of disagreement } & \multicolumn{3}{c}{ Native } & \multicolumn{2}{c}{ Persian } \\
\cline { 2 - 6 } & $f$ & $\mathrm{P}$ & $f$ & $\mathrm{P}$ \\
\hline 1 & Irrelevancy claims & 0 & 0 & 4 & $4 \%$ \\
2 & Challenges & 12 & $30 \%$ & 5 & $5 \%$ \\
3 & Contradictions & 13 & $32.5 \%$ & 9 & $9 \%$ \\
4 & Counterclaims & 7 & $17.5 \%$ & 12 & $12 \%$ \\
5 & Contradictions followed by counterclaims & 0 & 0 & 0 & 0 \\
\hline Note. $\mathrm{F}=$ frequency, P = percentage & & & &
\end{tabular}

As Table 6 represents, although in this situation there is the closest relationship between the interlocutors, subjects in Persian group tended more not to apply face threatening strategies while in native English speakers the percentage of using $\mathrm{CH}(30 \%)$ shows the face of the addressee was not much considered by them (e.g. Why don't you like it?).

\subsection{Situation 7}

Your babysitter offers you that one of your kids should be monitored by a psychiatrist. You think it's not 
Bavarsad, S. S., Eslami-Rasekh, A., \& Simin, S.

necessary to do this and completely disagree with her.

You say:"

In this situation it is the speaker who possesses higher power status. So, the speaker finds himself completely free for choosing face threatening strategies (irrelevance claims and challenges).

\section{Table 7}

Situation 7: Disagreement with babysitter

\begin{tabular}{llcccc}
\hline \multirow{2}{*}{ Types of disagreement } & \multicolumn{3}{c}{ Native } & \multicolumn{2}{c}{ Persian } \\
\cline { 2 - 5 } & $f$ & $\mathrm{P}$ & $f$ & $\mathrm{P}$ \\
\hline 1 & Irrelevancy claims & 3 & $7.5 \%$ & 7 & $7 \%$ \\
2 & Challenges & 9 & $22.5 \%$ & 13 & $13 \%$ \\
3 & Contradictions & 9 & $22.5 \%$ & 70 & $70 \%$ \\
4 & Counterclaims & 0 & 0 & 4 & $4 \%$ \\
5 & Contradictions followed by counterclaims & 0 & 0 & 0 & 0 \\
\hline Note. F= frequency, $\mathrm{P}$ = percentage & \multicolumn{3}{c}{} & &
\end{tabular}

As table 7 shows, CT in Persian speakers group was the most favored strategy with $70 \%$ (e.g. I disagree, mind your own business) while $\mathrm{CC}$ which is considered as the most polite way to show disagreement by not producing direct opposition with $4 \%$ was the least preferred one (e.g. I think my child has a normal behavior, it is not needed) but this strategy was completely absent by native English speakers.

\subsection{Situation 8}

You are sitting in a restaurant and ordering your favorite food. The waiter suggests not eating this food and trying the new one which is recently cooked in this restaurant. You disagree with his offer. You say:" .."

Just like the previous situation, in this situation the person who is disagreed with is in lower status and the main focus is on the role of social distance in choosing an appropriate disagreement strategies.

\section{Table 8}

Situation 8: Disagreement with a waiter

\begin{tabular}{llcccc}
\hline \multirow{2}{*}{ Types of disagreement } & \multicolumn{2}{c}{ Native } & \multicolumn{2}{c}{ Persian } \\
\cline { 3 - 6 } & & $f$ & $\mathrm{P}$ & $f$ & $\mathrm{P}$ \\
\hline 1 & Irrelevancy claims & 0 & 0 & 11 & $11 \%$ \\
2 & Challenges & 0 & 0 & 1 & $1 \%$ \\
3 & Contradictions & 14 & $35 \%$ & 15 & $15 \%$ \\
4 & Counterclaims & 17 & $42.5 \%$ & 11 & $11 \%$ \\
5 & Contradictions followed by counterclaims & 0 & 0 & 0 & 0 \\
\hline Note. F= frequency, $\mathrm{P}$ = percentage & \multicolumn{3}{c}{} & &
\end{tabular}

As it is shown in Table, Persian speakers used IC as the most face threatening strategy more than native English speakers (e.g. None of your business!) which shows power plays a very crucial role in applying the strategies.

\subsection{Situation 9}

You want to buy a house. The sweeper of that street tells you that there are a lot of problems in this quarter and it's better to buy a house two streets ahead. You have already searched about that quarter and you are sure about your choice. You disagree with him.

You say:" 
Disagreement strategies to suggestions between Persian EFL learners and American native English speakers

In this last situation, again the power inconsistency is focused on as the interlocutor in this situation seems to have the least power status.

\section{Table 9}

Situation 9: Disagreement with a sweeper

\begin{tabular}{llcccc}
\hline \multirow{2}{*}{ Types of disagreement } & \multicolumn{2}{c}{ Native } & \multicolumn{2}{c}{ Persian } \\
\cline { 3 - 6 } & & $f$ & $\mathrm{P}$ & $f$ & $\mathrm{P}$ \\
\hline 1 & Irrelevancy claims & 2 & $5 \%$ & 9 & $9 \%$ \\
2 & Challenges & 8 & $20 \%$ & 0 & 0 \\
3 & Contradictions & 14 & $35 \%$ & 18 & $18 \%$ \\
4 & Counterclaims & 4 & $10 \%$ & 5 & $5 \%$ \\
5 & Contradictions followed by counterclaims & 0 & 0 & 0 & 0 \\
\hline Note. F= frequency, P = percentage & & & &
\end{tabular}

According to Table 9, native English speakers had more tendencies to apply $\mathrm{CH}$ while showing disagreement with an interlocutor with the least possible power (e.g. Just go away). The last table summarizes and shows the application of strategies by both Persian EFL learners and native English speakers.

\section{Table 10}

General table showing the application of strategies for showing disagreement

\begin{tabular}{llcccc}
\hline \multirow{2}{*}{ Types of disagreement } & \multicolumn{2}{c}{ Native } & \multicolumn{2}{c}{ Persian } \\
\cline { 3 - 6 } & & $f$ & $\mathrm{P}$ & $f$ & $\mathrm{P}$ \\
\hline 1 & Irrelevancy claims & 8 & $2.2 \%$ & 45 & $5 \%$ \\
2 & Challenges & 62 & $17.2 \%$ & 56 & $6.21 \%$ \\
3 & Contradictions & 136 & $37.7 \%$ & 253 & $28.10 \%$ \\
4 & Counterclaims & 68 & $18.8 \%$ & 119 & $13.22 \%$ \\
5 & Contradictions followed by counterclaims & 1 & $0.27 \%$ & 41 & $4.55 \%$ \\
\hline Note. F= frequency, P = percentage & \multicolumn{3}{c}{} \\
\end{tabular}

Regarding Brown and Levinson taxonomy (1987), IC and $\mathrm{CH}$ were the most face threatening strategies to show disagreement while CC was the most polite way as no direct opposition is expressed by interlocutors. As Table 10 represents, native English speakers use face threatening strategies more than Persian EFL learners and less pay attention to the face of the addressee who is being disagreed and Persian EFL learners were more cautious to apply the strategies that keep the face of the interlocutors.

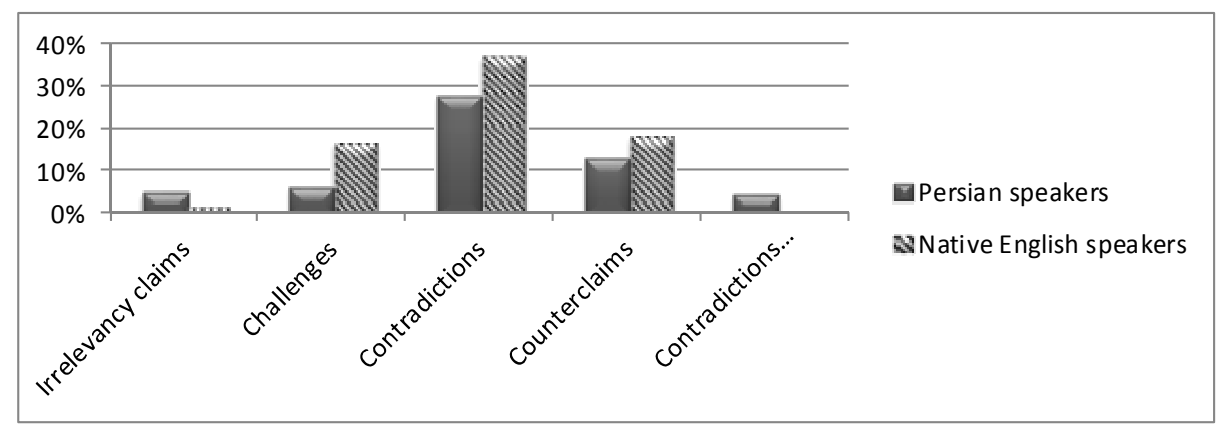

Figure 1. The application of strategies for showing disagreement

Beside these five types introduced by Muntigl and Turnbulls' taxonomy (1987), we could add four more patterns that were frequently used by Persian EFL learners which are closely related to culture and religion. These four patterns are introduced as Thanking, in which the disagreement to the situation starts with a thanking word (e.g. thanks, but I like it), Mitigation of apology, in which the participants start their disagreement with a word of apology, (e.g. sorry, but I don't like to change it), Providing reason, in which the participant tends to give reason instead of showing direct disagreement, (e.g. I don't like the other choices in the menu), Mitigation of God willing, which is completely related to Persian culture and religion (e.g. May be next time, God willing). All these patterns are considered to mitigate the threat to the face of the addressee and try to save the face of 
Bavarsad, S. S., Eslami-Rasekh, A., \& Simin, S.

interlocutors as there is no direct contradiction. Two of these patterns (Thanking and providing reason) were used by both nationalities while the other two patterns (Mitigation of apology and Mitigation of Apology) were not used at all by native English speakers. The following table shows the frequencies and percentages of applying these new found patterns in nine situations.

\section{Table 11}

General table showing the application of strategies for showing disagreement

\begin{tabular}{llcccc}
\hline \multirow{2}{*}{ Patterns } & \multicolumn{2}{c}{ Native } & \multicolumn{2}{c}{ Persian } \\
\cline { 3 - 6 } & & $f$ & $\mathrm{P}$ & $f$ & $\mathrm{P}$ \\
\hline 1 & Thanking & 34 & $9.44 \%$ & 52 & $5.77 \%$ \\
2 & Mitigation of apology & 0 & 0 & 11 & $1.22 \%$ \\
3 & Providing reason & 51 & $14.16 \%$ & 224 & $24.88 \%$ \\
4 & Mitigation of God willing & 0 & 0 & 14 & $1.55 \%$ \\
\hline Note. F= frequency, P = percentage & & &
\end{tabular}

Regarding Table 11, except in Thanking strategy, Persian EFL learners used these mitigating patterns much more than native English speakers in order to lessen the possible risk of threatening the addressee's face.

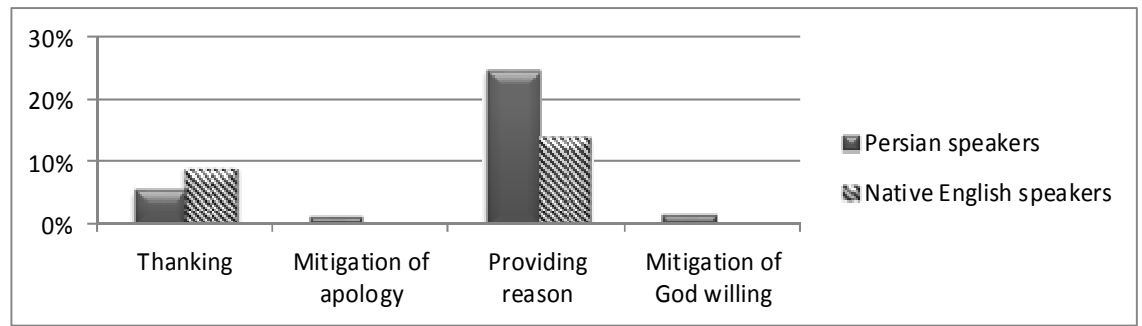

Figure 2. Applying the new found patterns by both Persian EFL learners and native English speakers

To answer the second question of the study the following statistics was done which shows an exact and clear result.

Table 12

Disagreement type, Language Cross tabulation

\begin{tabular}{lccc}
\hline \multirow{2}{*}{ Disagreement type } & \multicolumn{2}{c}{ Language } & \multirow{2}{*}{ Total } \\
\cline { 2 - 3 } & Persian & English & \\
\hline Irrelevancy claim & 8 & 45 & 53 \\
Challenges & 62 & 56 & 118 \\
Contradictions & 136 & 253 & 389 \\
Counterclaims & 68 & 119 & 187 \\
Contradictions followed by counterclaims & 1 & 41 & 42 \\
Total & 275 & 514 & 789 \\
\hline
\end{tabular}

Table 13

Chi-Square Tests

\begin{tabular}{lccc}
\hline \multicolumn{1}{c}{ Statistics } & Value & df & Asymp. Sig. (2-sided) \\
\hline Pearson Chi-Square & $21.366^{\mathrm{a}}$ & 4 & .000 \\
Likelihood Ratio & 22.564 & 4 & .000 \\
Linear-by-Linear Association & 11.442 & 1 & .001 \\
N of Valid Cases & 789 & & \\
\hline Note. a. 0 cells (.0\%) have expected count less than 5. The minimum expected count is 14.64 &
\end{tabular}

Note. a. 0 cells (.0\%) have expected count less than 5 . The minimum expected count is 14.64

Since Sig. (2-tailed) value was less than the level of significance (i.e. .000<.05), it could be concluded that Persian and English speakers were significantly different in terms of applying different types of disagreement strategies. 


\section{Discussion and conclusion}

Most people in most every day circumstances find it difficult when they want to settle disagreements. The question of language and power is also a controversial issue in pragmatics, sociolinguistics, and sociology. Yet, it is among the least investigated areas in Persian language use, even in the field of general linguistics. The present study tried to find and show the relationship between power and the application of disagreement strategies and of course to compare the strategies applied by two nationalities. The findings of this study indicate that there is a mutual relationship between power and the use of particular disagreement strategies by both Persian EFL learners and native English speakers. The results also proved that American English speakers and Persian EFL learners are significantly different in applying disagreement strategies as Iranian try to be more polite and cautious to save the face of the addressee by employing mitigating strategies and not preferring face threatening strategies.

To sum up, as mentioned by Heidari (2014) one can conclude that the Islamic culture of Iran can play a very important role to show conservative behaviors while disagreeing with different people in varying social status and cause people to employ the patterns which may be absent in other cultures but all are mitigating strategies which show the faces of interlocutors are so important to be saved when there is an opposition.

\subsection{Pedagogical implications}

Regarding the above mentioned results, the following implications are arisen. First, the findings may provide information to instructors who are responsible for designing and developing new materials for EFL learners. Second, as Heidari et al. (2014) mentioned "instructors can compare and contrast the speech patterns of the two languages in order to find the best way for presenting the materials". Finally, it is hoped that this crosscultural research enables the EFL teachers to adopt effective methods of teaching politeness strategies in the EFL classrooms.

\section{References}

Behnam, B., \& Niroomand, M. (2011). An investigation of Iranian EFL learners' use of politeness strategies and power relations in disagreement across different proficiency levels. English Language Teaching, 4(4), 204-220. http://dx.doi.org/10.5539/elt.v4n4p204

Brown, P., \& Levinson, S. C. (1987). Universals in language usage: Politeness phenomena In EN Goody (Ed.), Questions and politeness: Strategies in social interaction, (pp. 56-311). New York: Cambridge University Press.

Dogancay-Aktuna, S., \& Kamisli, S. (1996). Discourse of power and politeness: Through the act of disagreement. Paper Presented at the Annual Meeting of the American Association for Applied Linguistics (18th, Chicago, IL, March 23-26, 1996).

Guodong, L., \& Jing, H. (2005). A contrastive study on disagreement strategies for politeness between American English \& Mandarin Chinese. Asian EFL Journal, 10(1), 1-12.

Heidari, A., Simin, S., Eslami-Rasekh, A. (2014). Politeness strategies and power relations in disagreement. International Journal of Research Studies in Language Learning, 4(2), 1-10.

Kreutel, K. (2007). "I'm not agree with you". ESL learners' expressions of disagreement. Teaching English as a Second Language Electronic Journal, 11(3), 1-35.

Liu, S. (2004). Pragmatic strategies and power relations in disagreement: Chinese culture in higher education. New York: Universal Publishers.

Mehregan, M., Eslamirasekh, A., Dabaghi, A., \& Jafari S. D. (2013). Disagreement expressions in the discourse of young Persian speakers. Procedia-Social and Behavioral Sciences, 70, 598-604.

http://dx.doi.org/10.1016/j.sbspro.2013.01.098

Muntigl, P., \& Turnbull, W. (1998). Conversational structure and face work in arguing. Journal of Pragmatics, 29, 225-256. http://dx.doi.org/10.1016/S0378-2166(97)00048-9 
Bavarsad, S. S., Eslami-Rasekh, A., \& Simin, S.

Nguyen, T. P. T. (2009). Politeness strategies in showing disagreement in group work used by Vietnamese and American undergraduate students. Bachelor's Graduation Paper, Vietnam National University, English Department, university of languages and international studies.

Niroomand, M. (2012). An exploration of upper-intermediate Iranian EFL learners' perception of politeness Strategies and Power Relation in Disagreement. English Language Teaching, 5(10), 180-191. http://dx.doi.org/10.5539/elt.v5n10p180

Parvaresh, V., \& Eslami-Rasekh, A. (2009). Speech act disagreement among young women in Iran. Comparative Literature and Culture, 11(4), 2-8.

Pilkington, J. (1992). 'Don't try and make out that I'm nice!' The different strategies women and men use when gossiping'. Wellington Working Papers in Linguistics, 5, 37-60.

Simin, S., Eslami, Z. R., Eslami-Rasekh, A., \& Ketabi, S. (2014). The effect of explicit teaching of apologies on Persian EFL learners' performance: When e-communication helps. International Journal of Research Studies in Language Learning, 3(4), 1-14. http://dx.doi.org/10.5861/ijrsll.2014.661

Yule, G. (1996). Pragmatics. Oxford: Oxford University Press. 
Appendix A

English Version of the Discourse Completion Test (DCT)

Age: .............. Gender: .................. Degree:

Please read the following situations and answer. Researcher wants you to give appropriate answer in a completely normal manner. Thanks for your cooperation.

1. You visit your doctor due to your continuous headaches. $\mathrm{S} / \mathrm{H}$ e believes that you must change your method of treatment but you are completely satisfied with this method and you disagree with the doctor.

You say:.

2. You're driving on a highway that the police stops you and then fines you for not paying attention to the signs. He suggests you that it's better to participate in new classes of driving course which reeducates and reminds the signs. You feel no need to do this.

You say:

3. You see your child's school principal. He tells you it's better to change your child's major because its future will not be so good. You think contrary to him and your child is successful in this field. Then you disagree with him.

You say:

4. By coincidence, you see one of your old colleagues, Mr. Ahmadi, in the street and he tells you to change your hairstyle because it's not beautiful and you look older. Unlike him, you like this style a lot.

You say:

5. You are speaking with a neighbor and she suggests changing the caretaker of the building because she isn't pleased with him, but you are completely satisfied with him and reject this suggestion.

You say:

6. You buy a piece of clothes and come back home. When you put it on, your spouse says this color is not good on you and it's better to change the color. You disagree.

You say:.

7. Your babysitter offers you that one of your kids should be monitored by a psychiatrist. You think it's not necessary to do this and completely disagree with her.

You say:

8. You are sitting in a restaurant and ordering your favorite food. The waiter suggests not eating this food and trying the new one which is recently cooked in this restaurant. You disagree with his offer. You say:

9. You want to buy a house. The sweeper of that street tells you that there are a lot of problems in this quarter and it's better to buy a house two streets ahead. You have already searched about that quarter and you are sure about your choice. You disagree with him.

You say: 
Bavarsad, S. S., Eslami-Rasekh, A., \& Simin, S. 